\title{
African Cultural Perspective in Social Entrepreneurism: De-Fossilizing Western Ideologies in Muhammad Yunus' Mixed Concept Approach to Building Social Business
}

\author{
TANGYIE EVANI C.A \\ University of Bamenda \\ Department of Linguistics and African Languages \\ LEM Lilian ATANGA \\ University of Bamenda \\ Department of Linguistics and African Languages \\ Emmanuel NFORBI \\ University of Dschang \\ Department of linguistics and African Languages \\ Edmond BILOA \\ University of Dschang \\ Department of Linguistics and African Languages \\ NTONIFOR Helen \\ University of Dschang \\ Department of applied Foreign Languages
}

\begin{abstract}
Muhammad Yunus' book "Building Social Business: A new Kind of Capitalism that Serves Humanity's pressing Needs," presents findings from a mixed concept approach to social business based on the concept that social business is the new kind of Capitalism that serves humanity. From his onset vision of assisting the poor move out of subsistence levels, he created the "Grameen Bank" which means "village Bank" While Muhammad Yunus had as original plan to assist both men and women in the development process, it sooner became clear to him that women provided expected results than men and this led to a gradual shift from the target population as both men and women, to a concentration on the women fold. The book intends to account for an approach in social business that deals with socio-cultural aspects that focus on collective behavior as it constitutes one of the systems of cultures functioning within a holistic context of related socio-cultural economic patterns. As such, sustainable social business development does not only represent the expression from the sociological perspective but transcends to the level of societal acceptability. By applying a cross-cultural analytical lens to the problems plaguing social business in sub-Saharan Africa, and building on the ideas propagated by Yunus' this article will contribute to a better understanding of the fundamental changes in the nature and goals of building social business alongside cultural knowledge in the undeveloped economic systems of Sub Saharan Africa.
\end{abstract}

Keywords: Sociocultural, language, humanity, cultural knowledge, globalization, meaning

\section{Yunus' Social Business Vision}

In his book Building Social Business, Yunus argues that social businesses are more beneficial than mere charity organizations because charity encourages dependence among those being served while social business puts those being served in the position of being an active participant in the economy by encouraging entrepreneurship.

From the first sight one would agree with Yunus but if one examines the statement critically and especially from the Sub Saharan African perspectives, if would be difficult to accept the statement as such because Africa south of the Sahara has no policy in connection to the development of social entrepreneurship. 
While we agree with Yunus that social businesses are more beneficial in the case of developed economics, very poor economies like those of African countries south of the Sahara need primarily charity organizations which could latter develop and transform themselves into social businesses Within the same light Yunus goes on to argue that "poverty is not created by poor people, he purports that poverty is created by the system put in place, the institutions that have been designed, and the concepts that have been formulated. Within this concept of reasoning, Yunus is bringing us to seeing with him that all people, including the poor, are born with many gifts that will ultimately benefit human society if people are given the opportunity to express themselves because, as he argues, when someone is living in poverty "their life is wasted and the world suffers from not benefiting from the person's untapped talents".

The point Yunus is making here is very logical from a humanistic perspective. Yunus believes in egalitarianism and upholds human values that naturally run through his line of thoughts. But to think of a society where everyone has something valuable to offer may be utopic. our understanding of a fair and just society in line with Yunus would be one in which there is natural stratification and purposeful hierarchy. Stratification in terms of layered production or services provision and hierarchy in management and decision making. These are natural talents embedded in each and every one of us but these talents need to be developed, harnessed and applied wherever need be, within the framework of human development. However, the question of untapped talents and wasted life is preoccupying many young African scholars, who seem, not only seem indeed, but are rather trapped in the web of not having their talents tapped to the benefit of their father lands.

The ruling African class is of an average age of 70 . The economic effects of such a situation is what we experience today as the African economic backwardness. There is no doubt in the fact that the changing dynamics in the world order poses a lot of problems to people of the older generations because of the fast mutations brought about by innovative technologies and the ongoing complex process of globalization. Presentday youths or precisely young scholars have a better understanding of world issues and can make better appraisals within these changing dynamics or shifting paradigms. In our opinion and in line with Yunus, there is a lot to do in Africa within the frame of logic that "poverty is not created by poor people but rather by the system put in place, the institutions that have been designed, and the concepts that have been formulated. Within this frame of reasoning, Yunus is calling and drawing attention to the fact that all people, including the poor, are born with many gifts that will ultimately not benefit society if these people are not given the opportunity to express themselves because as he argues when someone is living in poverty his/her life is wasted and the world suffers from not benefiting from the person's untapped talents.

\section{Human Nature and Economics;}

According to Yunus, traditional capitalism as per western ideology portals individuals as unique dimensional beings that are only out for personal gains which in the world of economics implies making the highest possible profits. Though there is an element of truth in the statement, it would be also important to consider capitalism in the form of socially responsible business, as these are companies that operate within dual frames: making profit for their shareholders and contributing to a broader social good. As such, while we see the persistent increase in profit margins in the business policy of traditional capitalism, socially responsible businesses vary the degree to which profit marking motives affect decision and even the amount of profit designated for social activities. Nevertheless, Yunus however believes that people are multi-dimensional beings, of which self-interest exists but cannot explain one's entire makeup. This inability to explain the makeup resides in the very nature of man. Our perception of interest and as such, our desires and satisfactions are related to our location, background and interest. As varied as these are in fashioning our world views, so they are in building the differences within which every human society builds its own frame or system of behaviour. That is why Yunus acknowledges himself that "Once we begin to see people as multi-dimensional, capitalism can begin to include space for social businesses".

\subsection{Revisiting yunus' Social Business Concept}

From Yunus' analysis, we understand that there are two kinds of social business. Type one is a "Non-loss, Nondividend Company dedicated entirely to achieving a social goal." The other type is a "profit-making company owned by poor people, either directly or through a trust that is dedicated to predefined social cause. By implication, social businesses must be self-sustaining and its owners "must remain committed to never take any dividend beyond the return of the original amount they invested." 
But if we go by the second type of social business which is owned by the poor, how effective can this concept apply to them? This takes us to understanding why such business ventures cannot work in Sub Saharan Africa. When those who carry out a business initiative are poor, there is absolutely no hope for sustainability. This is because, for any business to get to maturity and profitability, many resources are needed including human and financial. Poor people naturally lack both the human capacity: - the technical skills needed to pilot the project, and the necessary capital to inject into the project. Many good ventures have died before maturity in most Sub Saharan African countries just because those concerned with the business are poor- they lack the education, the access to technology and at times are not healthy enough to carry out the task. In our opinion, any business venture, be it social oriented or capitalistic, require human resources and financial capital which are not always at the reach of the poor thus constituting a great handicap for the social progress of those who are less financial viable. Though one may argue that micro credit loans could provide seed capital for the poor, what is generally observed is that this micro-finance structures charge extraordinary high interest rates that at times end up rendering borrowers poorer. In the case of Sub-Saharan Africa, many non-governmental organizations and civil society organizations have decried the fact that microcredit structures do not work for the interest of the poor contrary to their mission. Governments is still to act on this problem, and the situation of the poor keeps deteriorating as the days go by, with no legislative to protect them, with no hope to be pull out of the web of poverty one day.

\subsection{Cultural Barriers In Social, Businesses}

Culture is a coercive force that causes people to see the world in a certain way. If this is the case people with different cultures will construct reality differently. The nature and type of social business developed by any given community will depend on the cultural environment which is equally greatly influenced by its technology. When dealing with this relationship between physical environment and cultural barriers, it is not easy to categorize the earth into neat ecological zones each with its own unique and mutually exclusive life. Nevertheless, Yunus concentrates his operational strategies in rural Communities in Bangladesh. Rural Bangladesh women are encouraged to stay close to the home so the company had to involve the entire Community in that when training these women to become sales people, often times they have to gain the approval of the husbands. Once the husbands became educated on the benefits of supporting their wives new career, women felt more comfortable in their new roles and sales increased as a result of this. This situation is not typical only to the Bangladesh community. In fact, many African cultures have restricted clauses to the total liberation and economic empowerment of the woman. This has greatly retarded the development pace of most African Nations. Today it is generally acknowledged that the woman constitutes a very powerful driving force of development. The specific mode of social business however, will be influenced by the interaction of the people's environment with its technology. It is technology (- apart of culture), that helps people adapt to other specific environments. In effect, the human species enjoys a tremendous adaptive advantage over all other species precisely because it has developed technological solutions to the problems of survival. Since some cultures have more complex technologies than others, they have gained greater control over their environments and hence social progress .For example, the complex social business technology used in America produces more social impact than that of Sub Saharan African countries that lack the technological environment and the human/financial resources. To suggest however those variations in technological adaptations exist, is not to imply that societies with simple technologies are either less intelligent or less able to cope with their environment. On the contrary, many societies with simple technologies adapt very ingeniously to their particular environment. This is the case with all the African counties south of the Sahara.

\section{Why Counter-Cultures are Necessary}

Many development scholars in remote cultural settings have argued that the process of "educating" husbands to allow wives to work and handle money runs counter to the existing traditional culture standards by which women are expected to adhere to, is "culturally insensitive." Yunus retaliates with, "culture is useless unless it is constantly challenged by a counter-culture. When people hide behind a culture, which we know to be a dead culture that is good for museum but not good for human society, there is a need to progress by adapting new trends. In other words, a healthy culture evolves with time and responds to the changing needs of a community. The problem with most social enterprises in Africa is the political condition under which they operate. The socioeconomic context within which most, if not all social enterprises operate is framed by political constrains that do not give room for objective management policies. 
By implication, those who are called upon to manage enterprises with a social orientation work within certain political lines that do not favour social development. For some development scholars, the general tendency is to believe that many African cooperate managers lack the skills and knowledge required to confront and challenge the existing economic statistics and to bring community development at the centre of the debate on sustainable development and democratization. While the African civil society has for the past years been so eager to see effective changes take place through economic growth and increase in social welfare benefits, social enterprise managers who attempt to look beyond their own job description for ways to improve and challenge the ongoing process are simply dropped out. This is in contrast with the objectives of the very economic innovative trends that ended up in the establishment of the concepts of social enterprise which in our opinion are very instrumental in setting up a new African model that attracts people in position of authority to accept change,- the change required to articulate the shared vision needed for any meaningful development geared towards both economic and technological advancements in sub Saharan Africa.

Research reveals that, for the past 25 years, social enterprise has changed and is shaping the course of economic progress in many developed nations through the introduction of significant development innovations in the economy at a local, national and international level. How then can African nations understand and make effective use of the growing popularity of social entrepreneurism for economic development, and how do social ventures fit into the wider social context of sustainable development within the uncertain business climate of Sub Saharan Africa?

In most of global development studies, sub Saharan Africa represents a prolonged underdevelopment crisis. Despite resent remarkable development gains driven by a combination of factors like increasing democratization and transparency, strengthening and reform of governance institutions, surge in commodity prices, and the adoption and implementation of more effective macro-economic policies, Sub Saharan Africa still faces daunting sustainable development challenges. While some interesting research has been conducted on sustainability challenges in Africa, the first striking result is the contrasting impacts. As the African Development Bank observed in its 2015 African development report, sound environmental management and effective governance are indispensable policy frameworks to ensure that Africa's natural resource wealth generates rapid development schemes to reduce poverty. In order to be successful, these frameworks must be transparent, accountable, inclusively representative, and take into account public participation

\subsection{Lessons Learned}

Yunus has enumerated a number of points as lessons in the course of establishing social business. Of these points some could be classified as motivational, others environmental and yet others as technical. The motivational points are in relation to never losing sight of the central goal of the social business. The more defined an objective is the more focused the strategies to attain the set objectives are. The environmental lessons are linked to the cultural set- ups of the geographic regions where the business is located. It is important for us to closely examine these cultural setups because, to look at the cultural dimension of development is in a way to look at how people interact and communicate in view of mobilizing, motivating and energizing people to make use of available resources in the realization of a common vision of collective progress. From this point of view, culture can be considered a force that makes people act in a particular way depending on how it is used. Social business could take any form but personal, social and cultural factors will influence such a choice. Whatever the choice is, we are using language to mean something or to explain an action and there is always a sharp dichotomy in the way language is used in creating cohesion within a community, be it for economic or for social purpose. Communicating in any culture will necessitate the command of a different set of options and alternatives from any other, but the extent to which any individual can convey meaning in a cultural context determines the reality he or she perceives. Hence the different realities for those who have grown through with the culture and lived with it from those who have learned the language but have not lived it. It is within this framework that Yunus is examining issues of culture in relation to social business development.

\subsection{How Culture Influences Social Business}

Culture makes it possible for its users to satisfy the basic function of social cohesion. If by culture we mean everything that people have, think and do as members of a society. This consideration is crucial in social business because the three verbs correspond to the three major components of culture. That is, everything that people have refers to material possession; everything that people do refers to those things they carry around in their heads, such as ideas, values and attitudes; and every thin that people do refers to behaviour patterns. 
Thus all cultures comprise a) material objects, b) ideas, values, and attitudes and c) patterned ways of behaving. The power of language to reshape ideas is recognized throughout history and social studies experts (William Benedict 2013, Regional Hopkins 2013) agree that "meanings are created as one interprets a message singly and collectively." However, Adama Ouane lays emphases on the point that "multiple meanings can exist from the same set of messages." While it is likely that those who share the same language experience within the same speech community will create similar meaning from the experience, it is "unlikely that everyone else will create the same meaning."(Ouane p.26). The whole process of social business is built on complex concepts of growth, evolution and maturation. This makes it difficult for those who use the word to free themselves from the web of meaning that impact a specific blindness to their language thought and action (Sachs 2010, p.6). Development is connected to the way we think and how we see the world around us. This is embedded and reflected in the language we use. For this reason, it ends up creating meanings that differ from others within the same community. Watson in his article: "Power, Development and Geopolitical changes" (1999), argues that the complex nature of language issues facing development has always placed language at the centre of development. He contends that development discourse has been dominated by economist, policymakers, political sciences or policy analysts whereas these issues equally concern interdisciplinary scholars since language issues play a central role in development. The point Watson is making here is very important in that this approach does not foster development in a sustainable way. Social business should be framed within the contexts of peoples' culture, that is, around the concept on which their experiences, attitudes and knowledge concepts are framed. That concept is nothing else than their language. It is possible to have an argument about poverty or social business without ever realizing that all of us are using the words to represent entirely different things. It's for this reason that Yunus emphasises on the need to beimmersed in the culture of the people that one intends to serve. In addition to this immersion, one needs some essential personal attributes including creativity, entrepreneurial spirit, the desire to make this world a better place, the ability to put ideas into action and a strong work ethic encompassed in an openness to new ways of doing things. Yunus also encourages his readers not to fret if they are having a difficult time identifying a problem they want to solve. He goes on to explain that one can simply find a group of people he/she wants to help and fight out a way to empower them by giving them "better access to the markets of the developed world, or by giving them good jobs, or by giving them income through business ownership."

\section{Planning for Social Business}

There are many ways of getting involved in social business. This may be through replicating an existing model in the community one wants to serve, creating a new venture or simply adding value to an existing venture. Yunus believes that our world is ripe for much needed changes and goes on to explain that by simply completing "the half-built theoretical framework of capitalism, by including social business" would allow us to begin the process of turning around the complex, global crisis we are now facing.

Social studies scholars conceive social business as a way to redress some of the inequalities witness across the continents. Ethical leaders in business as well as in public services are the future for African economic development. To some extent, we understand these, though such leaders are still lacking in its vast majority in the African continent, the next generation of leaders will certainly be more ethical and more conscious of the consequences of their actions.

We equally have the strong view that social business offers a better chance of success than relying on a stream of international donations to solve African economic problems. But the real problem remains that of financial, human and technological resources. It is worth stating here that since the advents of the economic crises, many African populations do no longer have collateral; hence do not have access to credit facilities as seed funding for social business creation. Without this credit facility, the greater majority of credit seekers considered as the poor cannot borrow to grow and expand their businesses, which is a contributing factor to the early stage business failure rate in sub Saharan Africa. Addressing challenges like this, understanding what needs to change for African economic dreams to come true, and then influencing the right people and working in partnership to get the job done, is what the African economic development vision should look forward to.

\subsection{Conclusion}

The problems that Africa faces are not going to respond to quick fixes. Although it is realistic to associate the Western concepts to the African development battle, we still have to clearly define the role the West has to play in the process. 
According to De Waele, the innovative use of technology and the capacity for self-sufficiency are Africa's key features of social business. Africa within the present global context must think out the old not for profit model of raising funds to distribute to other people. Today, even big NGOs need huge marketing campaigns and that is a huge overhead, so charity for charity does not really work anymore. With access to the internet and crowd funding, organizations can choose what they really want to fund. Of course, it is a good thing that big NGOs do things like distribute food, but in the end they are not helping efforts to make people self-sufficient, by growing their own food for example.

Yunus says that social business ventures have an important role to play in all of this, certainly by continuing to provide technological access, but also by helping to develop a supportive ecosystem, by connecting entrepreneurs, investors, business and mentors through programs or hubs. He stresses on the point that connecting social life with investment ventures centered on capacity building in favour of women is crucial to African sustainable development. Social business development that incorporates strategies in view of ameliorating Sub-Saharan African countries economic leadership potentials to construct social networks that impact their social understanding of community development are indispensable.

We argue that, this approach offers great sociological alliances thereby providing opportunities for social cohesion. From this perspective, Yunus' book underscores the pertinence of implementing a collective driven social business approach in countries with low income populations as the case with Bangladesh. The ultimate outcome in such an approach is that, it catalyzes the resilience of social business and the ability to make community asset building a social obligation. Considering the present policy of community development in most Sub Saharan African countries, One would not be wrong to argue that western concepts and approaches to enhance development in Sub-Saharan Africa are stripped off from socio-cultural realities thus extricating a community vision to the benefit of a few educated that in turn impedes the chances of sustainability. Social business development as perceived through the lens of a collective entity by development scholars and practitioners is yet to be given adequate attention in regions where the vast majorities are low income people as is the case with sub-Saharan Africa. Whereas in the practice of social business venture, it is recognized that different societies have patterns of their own that are worth considering in the process of development since these patterns intersect with those of social organization and cultural dynamics. Present approaches have not sufficiently accounted for such a state in Cameroon.

How can the sociology of development enhance the understanding of the global concept of social business development in Sub-Saharan African, within the concept of globalization, and why not envisage an enabling environment for social business development? These are pressing questions that African development scholars must respond to and implement otherwise Sub Saharan Africa will more than ever before be left out in the race for global sustainable development and social progress.

\subsection{References}

Hopkins, R.(2013) African cultural consciousness and African-centered Historiography as preconditions for Wilson's New world Order Journal of Pan African studies, Vol.6 N 2, July 2013publication: London

Desmond, S. and Elfert, M.(2008). Family literacy, experiences from Africa and around the world, UNESCO institute for lifelong learning

Wolfgang, S. (2010).The Development Dictionary: A guide to knowledge as power. Zed Books London\& New York

Yunus M. (2010) Building Social Business: A new Kind of Capitalism that Serves Humanity's pressing Needs. 